\title{
The Ethics of Laying Hen Genetics
}

\section{Mia Fernyhough ${ }^{1}$. Christine J. Nicol ${ }^{2} \cdot$ Teun van de Braak ${ }^{3} \cdot$ Michael J. Toscano $^{4}$. Morten Tønnessen ${ }^{5}$ (D)}

Accepted: 11 November 2019 / Published online: 22 November 2019

(c) The Author(s) 2019

\begin{abstract}
Despite societal concerns about the welfare of commercial laying hens, little attention has been paid to the welfare implications of the choices made by the genetics companies involved with their breeding. These choices regarding trait selection and other aspects of breeding significantly affect living conditions for the more than 7 billion laying hens in the world. However, these companies must consider a number of different commercial and societal interests, beyond animal welfare concerns. In this article we map some of the relevant dilemmas faced by genetics companies in order to outline the scope of opportunities to improve welfare under current market conditions. This includes identifying cases where different animal welfare concerns conflict. We discuss the moral responsibility of laying hen genetics companies and the welfare implications that derive from the choices they make and the policies they follow. In addition to evaluating a selection of predominant current practices and breeding goals, we outline different angles from where to assess the moral legitimacy of various industry practices and policies. We discuss specific issues such as injurious pecking, bone health, induced moulting, chick culling and the circumstances of breeding stock.
\end{abstract}

Keywords Laying hens $\cdot$ Genetics $\cdot$ Breeding $\cdot$ Egg production $\cdot$ Animal ethics · Animal welfare

Morten Tønnessen

morten.tonnessen@uis.no; mortentoennessen@gmail.com

1 Farm Animals Department, Royal Society for the Prevention of Cruelty to Animals, Southwater, UK

2 The Royal Veterinary College, University of London, London, UK

3 Hendrix Genetics Laying Hens, Hendrix Genetics, Boxmeer, The Netherlands

4 Center for Proper Housing: Poultry and Rabbits (ZTHZ), University of Bern, Bern, Switzerland

5 Department of Social Studies, University of Stavanger, Stavanger, Norway 


\section{Introduction}

Societal concern for laying hen welfare has focused largely on conditions onfarm, such as the system of production (cage vs. non-cage; indoor vs. outdoor), opportunities for natural behaviours and practices involving mutilation. The impact of genetics on their welfare has received far less scrutiny, in contrast with other areas of livestock production, where the issues of high genetic milk yield in dairy production and meat yields in broiler production, have received high profile attention (e.g. European Chicken Commitment 2018; Joint Animal Protection Statement on the Welfare of Broiler Chickens 2018). However, the influence of genetics on laying hen welfare is clear, with strong genetic effects on traits including immune function (Bridle et al. 2006), bone strength (Stratmann et al. 2016; Candelotto et al. 2017), feather pecking, plumage condition, and associated mortality (Su et al. 2005; Brinker et al. 2014; Muir et al. 2014) and fearfulness (Uitdehaag et al. 2008; de Haas et al. 2014a). There is therefore great potential for genetics companies to influence the welfare of laying hens by appropriate analysis and consideration.

The global population of laying hens stands at between 6.1 billion (International Egg Commission 2018b, p. 22) and 7.6 billion (FAOSTAT 2018). Of these, the vast majority producing eggs for commercial production outside China are breeds from either of two European-based global genetics companies, Hendrix Genetics and Erich Wesjohann Group GmbH (EW Group). These two global leaders have a dominant position in most markets (Howard 2016). However, a third company Novogen-owned by Groupe Grimaud-emerged in 2008 as a 'new alternative in a highly consolidated market', with a global market share of around 6\% in 2012 (Bal 2012). In China, the world's single biggest egg market, the Chinese company Yukou has more than half of the market (Tao 2012; Windhorst 2019), making Yukou the third biggest layer breeding company globally, ahead of Novogen.

\section{Genetics Companies and Their Impacts on Hen Welfare}

The impact of genetics companies on the welfare of commercial laying hens cannot be appreciated without an understanding of the structure of the breeding industry and how breeds (and their respective traits) reach production facilities. Figure 1 provides an illustration of the relative number of birds at each stage of the egg production chain.

Although the two major companies retain distinctive 'brands' and subsidiary companies, the continued prioritisation of production traits (Preisinger 2017) has resulted in relatively uniform high production and performance outcomes across the different breeds (Table 1). Similar to other highly selected agricultural animals, intensive breeding for high production has resulted in a number of related welfare issues (Nicol 2015), with breed differences apparent in certain welfare parameters including fearfulness (Uitdehaag et al. 2008), susceptibility to bone fractures (Candelotto et al. 2017) and feather cover (Mullan et al. 2016), each of 


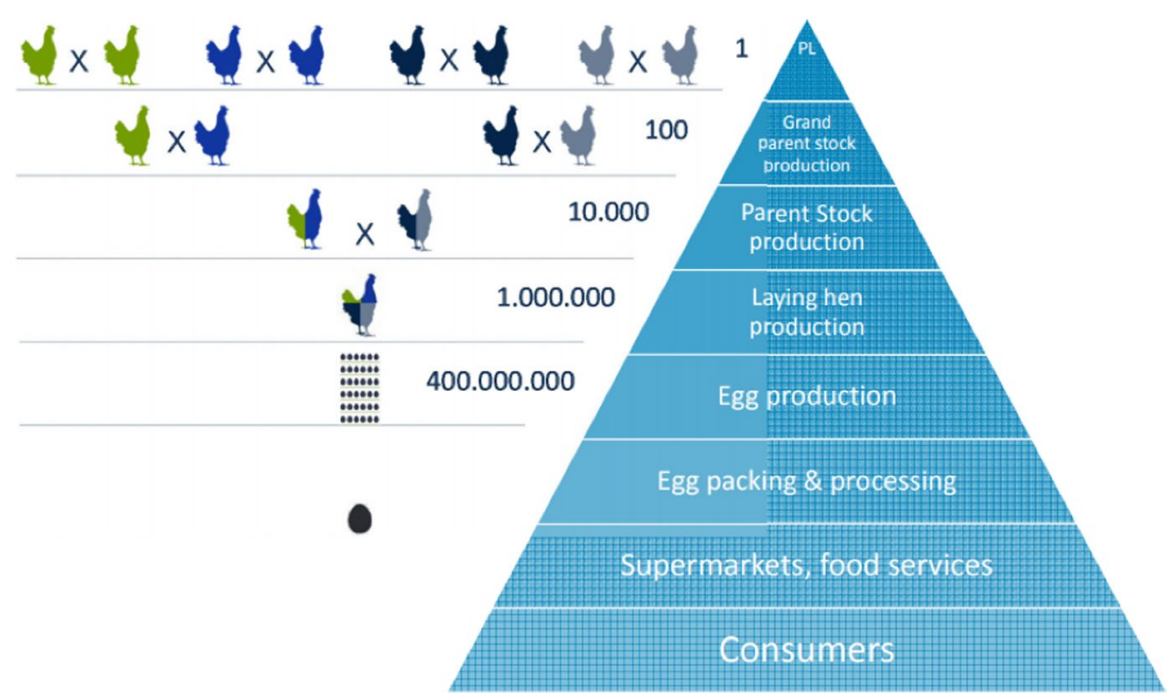

Fig. 1 Overview of the egg supply chain, including relative numbers of animals and products at each level

which is also influenced by management and environmental factors. Nonetheless, these concerns are present to varying degrees in all breeds.

Market differences in breeds used are often explained by consumer preferences, for example in relation to egg shell colour, rather than a general drive towards improved welfare outcomes. The British Blacktail breed exclusive to one UK supermarket was developed specifically for UK free-range conditions (personal communication), but perhaps more successfully achieves a unique selling point for the retailer rather than representing a solution to prevailing welfare concerns (see Mullan et al. 2016). A focus on ever improving performance indicators and a lack of scientifically validated 'higher welfare breeds' suggests welfare improvement may be limited by what is commercially feasible for particular markets. For example, the ISA Warren, which Hendrix describe as a higher welfare breed (personal communication), appears to have a lower production value (eggs per hen housed) than other commercial breeds (Table 1). However, there is no publicly available systematic information regarding objective welfare outcomes. Generally, conditions on farms are not as ideal as those of the breeding companies, with average mortality rates close to $8 \%$ at 60 weeks (Weeks et al. 2016) exceeding published targets. This might imply that conditions on farms have room for improvement, that the birds of the breeding companies are not robust enough for current farm practices, and/or that breeding in small groups is not directly comparable to housing in large groups.

There are commercial, economic and environmental drivers for continued genetic improvements in production indices such as eggs per hen housed and feed efficiency (Preisinger 2017). The progress in genetic improvement is such that the biological limit of an egg a day at peak lay is a reality, and to deliver continued commercial and economic benefit, genetics companies are now targeting extended laying cycles. 


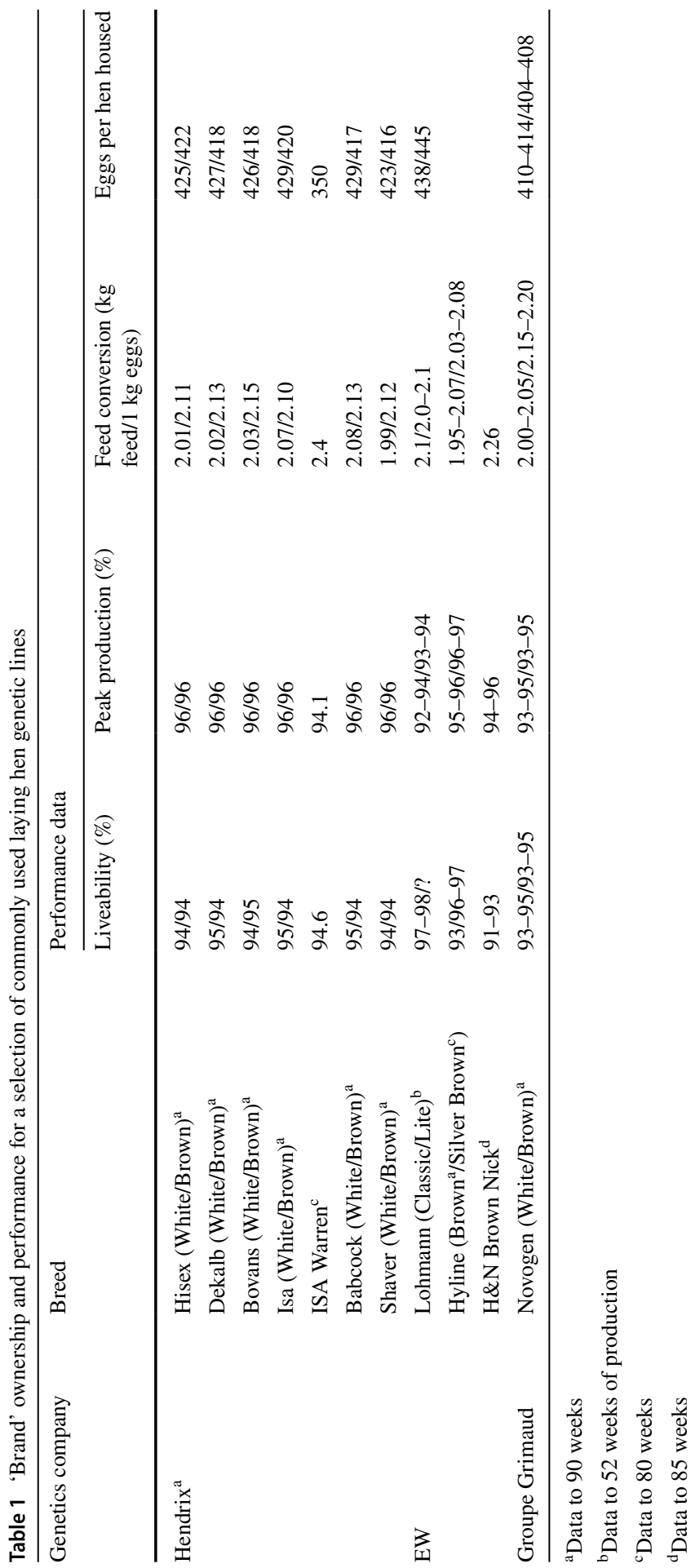


Where a producer may have realised 313 eggs per hen housed in 2010 (Preisinger 2017), the current expectation is over 400 (Table 1) with a future goal of 500 eggs per hen housed over a 100 week period (Bain et al. 2016).

Selecting almost exclusively for production traits has suited a primarily caged market where social interactions and environmental stressors, such as temperature variability, are limited. Although caged housing systems still predominate globally, the growing market for alternative (cage-free) production-and to a lesser degree the movement to enriched cages or colony cages in some markets-means that birds increasingly experience much more complex and varied social and environmental conditions, with the potential to exacerbate problems such as injurious pecking (IP) and keel bone damage (KBD) (Nicol 2015). Selection merely on production traits is no longer sufficient to meet all market demands, and a wider range of traits relevant to hen welfare are now included within breeding goals (Bain et al. 2016; Hendrix Genetics 2018) using ever more sophisticated techniques. Although selection on welfare parameters is reported, the relative weighting of such traits compared to production values is not publicly available and may be considered a 'closely guarded secret' (Nicol 2015).

Many welfare traits of importance in alternative systems, such as ranging behaviour, perching ability and social interactions may be difficult to measure and have low heritability compared to production indices, especially at onset and for prolonged laying cycles (e.g. Bennewitz et al. 2014 estimates feather pecking behavior at $\sim 0.1$ and egg production at $\sim 0.4$ ). The use of genomic information to enhance phenotypic data may help to deliver more rapid genetic improvements in these kinds of traits (Muir et al. 2014). Genetic engineering (GE) is viewed by many as an important step towards improving genetic (Jaffe 2018) — and even welfare-performance whilst being viewed by others as unethical in terms of the risks to human and animal health, welfare and environmental concerns (RSPCA 2017a).

\section{Genetics Companies and Their Wider Ethical Impacts}

Together with animal welfare, social justice, environmental sustainability and economic viability may be considered as part of the wider sustainability agenda and being of societal importance in the context of egg production (Fig. 2).

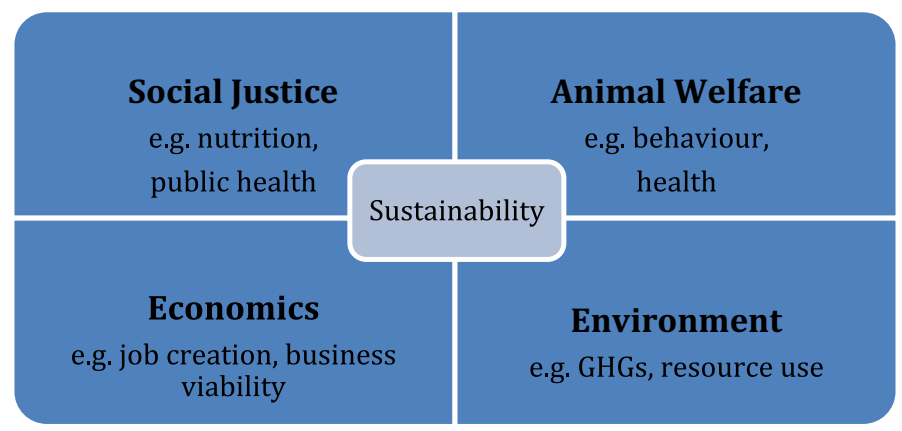

Fig. 2 The wider sustainability agenda related to egg production 
The actions of genetics companies may have significant economic (for example, via job creation), environmental (D'Silva and Webster 2010; FAO 2006) and health and welfare (both human and animal) implications of wider societal interest and importance. With regard to public health, for example, a loss of genetic diversity (Howard 2016; Muir et al. 2008) resulting from global market dominance in most markets by only two companies (see Besbes et al. 2007 for an overview) may have implications for the spread of Avian influenza. Although the current article touches on the ethical considerations of genetics companies in relation to these wider societal concerns, our focus is primarily on their animal welfare impact.

\section{Ethical Perspective on Animal Welfare}

Before our discussion and ethical analysis of issues relating to laying hen genetics can commence, we must first introduce the ethical perspectives that could be applied in that analysis.

The first approach is one that considers animal sentience as a key attribute for inclusion within an ethical framework. For Peter Singer (2002 [1975], p. 9), "the capacity for suffering and enjoyment is a prerequisite for having interests at all". Thus, the capacity of a chick, pullet or hen to have conscious experience of its own emotional states, is crucial. Emotional states such as fear, anticipation, comfort or pain have (often strongly) valenced positive or negative components-they refer to situations that an animal attempts to seek out or avoid. Although the private nature of the subjective experience cannot be known, there is growing circumstantial evidence concerning chicken experience (Marino 2017). For example, laying hens with keel fractures adjust their daily movement and location patterns (Candelotto et al. 2017) and prefer places where they have received analgesic drugs (Nasr et al. 2013), suggesting that cognitive processing of pain occurs in these birds.

Once it is accepted that chickens have interests in avoiding pain, or achieving comfort, then these interests have to be considered against other potentially competing interests. Singer (2002 [1975]) advocates a utilitarian approach where equal interests are considered equally, and actions are taken to minimise overall suffering of the participants in question. Thus, the pain experienced by a chicken may have to be balanced against direct human interests (e.g. in obtaining inexpensive and healthy food). Humans may also have diverse and indirect interests in maintaining a healthy and aesthetically pleasing environment or promoting a low-carbon economy. It should also be recognised that many people care deeply about animals and therefore feel happier if they perceive that animals are leading good lives (Dawkins 2016). Other ethicists (Regan 1983; Haynes 2008) have advocated an extension of rights to animals, so that their baseline interests (e.g. in avoiding severe pain) cannot be overturned, no matter what the economic interests of humans.

A second approach, focusing on an animal's capabilities (Nussbaum 2004) has many synergies with the demands and approaches of those setting and applying animal welfare standards. This approach demands that animals be able to perform natural behaviours and the opportunity for positive welfare experiences as well as the absence of negative ones. Rather than the abolition of animal use, Nussbaum 
calls for improvements wherever they can be made; a stance taken by many welfare organisations in a range of animal-use settings (see for example the policies of RSPCA, Dierenbescherming, Humane Society International). The idea of animals 'flourishing', e.g. engaging in play, pleasure and positive social interactions, is central to Nussbaum's theory. In some senses, Dawkin's (2008) 'two questions approach' mirrors these key demands. «Improvements in animal welfare», says Dawkins (ibid, p. 937), «can be based on the answers to two questions: Q1: Will it improve animal health? and Q2: Will it give the animals something they want?». Phrased differently, Dawkins asks what an animal needs (for health and behavioural satisfaction), and what it wants reflecting the opportunities for pleasure.

Below we discuss dilemmas facing laying hens genetics companies in relation to the outlined ethical concepts.

\section{Ethical Considerations of Genetics Companies}

\section{Genetics Companies' Impacts on Commercial Bird Welfare}

\section{Injurious Pecking}

Injurious pecking (IP) is an abnormal pecking behaviour directed at the feathers and skin of other birds. Although primarily considered a redirected foraging behaviour, its aetiology is multifactorial (see Nicol 2019 for a detailed review). Regarding welfare, IP can result in feather loss and cannibalism which can be painful, may increase risk of infection and the rate of mortality (Weeks et al. 2011), and is associated with flock fearfulness (de Haas et al. 2014b). It may also be associated with reduced production and increased feed intake.

To reduce the damage caused by IP, a majority of flocks globally are beak trimmed (Riber and Hinrichsen 2017) using a hot blade method before 10 days of age or using infrared technology shortly after hatching. However, as the beak is a sensitive organ used in exploration of the environment (Garnham and Løvlie 2018), beak trimming - a mutilation — affects the birds' perceptual opportunities and is a welfare concern in itself. Alternatives, such as physical beak blunting (e.g. using the 'PickPuck', Big Dutchman 2016) have been investigated, but such measures deal only with the symptom and not the causes of IP and, even in beak trimmed flocks, IP still occurs.

In markets where beak trimming is not permitted, as well as in those seeking to improve feather cover and overall welfare, single or multiple on-farm interventions may be employed (e.g. Lambton et al. 2013). Some, such as dimming of lights, may be problematic for welfare, resulting in reduced visual acuity, reduced activity and impaired social interactions - undoubtedly affecting the birds" "flourishing" and therefore being unacceptable from a capabilities perspective. Other interventions enhance positive behavioural opportunities, through environmental enrichment or range provision or by reducing the possibility of negative interactions by better stock-keeper interactions and reduced stocking densities. However, none of these methods is "fool-proof" and IP may still occur. 
Brown hybrids are more sensitive to environmental 'challenges' than white hybrids (de Haas et al. 2014a), suggesting that genetic improvements may enhance the success of on-farm interventions. Indeed, white hybrids generally demonstrate reduced IP behaviour and are more widely used in many (e.g. Norway, Sweden), but not all (e.g. Austria, Germany) countries where beak trimming is banned. International Egg Commission (IEC) data (2018a) suggests an increased use of white breeds when intact beaks become mandatory. In the Netherlands, white breed use has increased from $45 \%$ in 2013 to $65 \%$ in 2017. Although genetic improvement to reduce IP is possible (Su et al. 2005; Brinker et al. 2014), it will only provide a true solution if welfare is improved overall (Dawkins 2016). It is crucial that birds are not bred for docility, reduced sensory perception or a lack of environmental engagement. One extreme example of such an approach is the 'Smokey Joe' chicken, with programmed retinal degeneration. There is ongoing research into how these blind birds 'could be used to benefit the industry' (The Poultry Site 2007), as they cannot target the feathers of their conspecifics, but relying on such sensorial deprivation is unlikely to garner public support, and would not be morally acceptable according to any of the ethical principles discussed in Sect. 2.

It is clear that there is: (a) consumer and government appetite for rearing birds without beak mutilations, especially in certain European countries, (b) a need to support on-farm interventions to reduce levels of injurious pecking and (c) scope for genetic improvement. Genetics companies therefore face a challenge of developing layers with low propensity to perform IP, possibly in combination with particular management protocols, without adversely affecting the birds' behavioural integrity. The combination of these criteria is likely to compromise productivity (Bennewitz et al. 2014) and the ethical arguments for and against this position will be discussed later in the paper.

\section{Bone Health}

Bone health has long been a reported problem in commercial laying hens (Warren 1937; Grumbles 1959) with a recent focus in the last 20 years on damage (fractures) to the keel (KBF) (Toscano 2018). In barren battery cages, a lack of exercise and the high calcium requirements of prolific egg production resulted in a severe osteoporotic condition known as "cage layer fatigue" or "cage paralysis" (Grumbles 1959) resulting in brittle bones (including the spine), paralysis and death. The additional opportunity for exercise in enriched cages and alternative systems improves bone health (Fleming et al. 1994), but also results in increases opportunities for collisions with the environment, which can lead to KBF. Overall, higher rates of KBF occur in alternative systems (28-89\%) than in cages (22-44\%) (Sherwin et al. 2010; Wilkins et al. 2011), with rates increased further in systems with elevated perches or tiers (Sandilands et al. 2009; Harlander-Matauschek et al. 2015; Stratmann et al. 2015). The unacceptably high level of KBF in all systems (Heerkens et al. 2016; Wilkins et al. 2011) and evidence that these fractures are painful and alter behaviour (Nasr et al. 2013) suggests KBF is a significant welfare concern.

Selective breeding for productivity traits means that the calcium required for egg shell production is greater than the medullary bone can supply; structural bone 
becomes utilised in egg shell production and subsequently bones become osteoporotic, resulting in bone fragility. Once a fracture occurs, egg production appears to fall, suggesting there is a tradeoff or re-partitioning of resources within the hen (Rufener et al. 2018). But whether KBF occurs as a result of osteoporosis is unclear (Gebhardt-Henrich et al. 2017), with other factors including nutrition playing a role (Tarlton et al. 2013; Toscano et al. 2015). The move away from caged production systems thus provides a challenge for genetics companies in terms of developing sufficiently robust birds for complex cage-free environments (Stratmann et al. 2016; Candelotto et al. 2017).

Given the multifactorial nature of $\mathrm{KBF}$, genetic selection is just one potential approach, but Fleming et al. (2006) suggested that this would have the greatest potential for long-lasting effect. Genetic effects could be direct (e.g., greater bone strength) or indirect (e.g. greater activity leading to increased bone strength). As with IP, the welfare aim should be to reduce the current welfare concerns-meeting the animals' needs-whilst enabling the full range of natural and highly motivated behaviours - meeting the animals' wants (Dawkins 2008). The best strategies on this basis are those which improve skeletal health and the birds' ability to successfully navigate its environment rather than those which prevent species-specific behaviours (wing flapping, perching). In consequence, whilst the lowest incidence of KBF occurs in barren battery cages (Sherwin et al. 2010) cage housing would not be advocated as a solution using our ethical framework.

Studies suggest there is potential to utilise genetic selection techniques to improve rates of keel bone damage (Stratmann et al. 2016; Fleming et al. 2004) although this may be to the detriment of laying performance (Regmi et al. 2016; Stratmann et al. 2016) and egg shell qualities (Nasr et al. 2012). A greater number of experimental studies conducted in conditions that are relevant and representative to the global bird population and the various housing conditions therein, would be invaluable to allow genetics companies the ability to better gauge the benefits and true costs of intervention. Nonetheless, given the currently available information and published reports, a genetic solution to KBD may need to align with a reduced focus on productivity, a topic discussed later.

\section{Extended Laying Cycles}

Increasing commercial strain laying persistence, e.g. to 100 weeks (500 eggs), appears to be a universal goal of genetics companies (Bain et al. 2016). Extended laying periods reduce the number of required replacement birds and could have a positive impact in terms of resource use. Although there may be benefits in terms of sustainability, economics and welfare-if supported by good welfare outcomes at end of lay - there may be other negative economic consequences, e.g. for pullet rearers who will experience reduced demand for their product. It is possible however that the balance could be redressed if pullet rearers are compensated by the egg producers who see financial benefit.

It is estimated that the UK flock could be reduced by 2.5 million laying hensincluding breeding stock-with 100 week laying cycles (Bain et al. 2016). Welfare 
benefits may be particularly evident in markets where induced moulting is currently practiced; if a 100 week laying cycle is economically comparable with a typical cycle involving moulting, the economic justifications for moulting would be obsolete. Moulting involves the loss of around $25 \%$ of a hen's body weight and, even using non-feed withdrawal methods, may result in mortality of around $20 \%$ (first 10 days of moulting and the post-moulting period, Sariozkan et al. 2016). Moulting is unacceptable when considered by any of the ethical perspectives discussed.

A longer life may only be considered of benefit to the hen, however, if good welfare is present and maintained. Some measures of welfare at end of lay are currently poor, including incidence of $\mathrm{KBF}$, emaciation, parasite burden and poor feather cover (Sherwin et al. 2010). Only if these issues can be effectively addressed, through better management and/or increased robustness could extended laying cycles be justified on the basis of laying hen welfare. Good welfare cannot arise from trade-offs between different requirements and thus, improved physical health must be accompanied by positive outcomes for all other welfare-relevant indicators.

The aim then for genetics companies should not only focus on extending laying cycles, but also on improving robustness to ensure birds can cope both physically and mentally with a longer productive life. Current efforts are underway to address hen stress adaptability from a genetic perspective in combination with traditional welfare assessments (e.g., bone health, footpad health) and more novel approaches (e.g., hippocampal neurogenesis, Smulders 2017). These approaches should be included in the ensuing discussions.

Beyond welfare, whether or not extended laying cycles are ethically justifiable depends on whether a balance can be struck between economic, animal welfare and environmental concerns which is discussed in our later ethical analysis.

\section{Culling Day Old Males}

The development of egg and meat specific breeds has resulted within the egg industry in redundant males which are killed shortly after hatching. The culling of day old male chicks is a highly emotive issue and receives a high profile from campaigning organisations. Despite this high profile, and the commitments of major corporations such as Unilever to phase out the practice within their supply chains, public awareness appears relatively low.

Current options for the cessation of the practice include in-ovo-sexing (Galli et al. 2017; Weissmann et al. 2013) or the development of dual purpose breeds suitable for both egg and meat production. However, in surveys of Dutch citizens, there was little consensus about acceptable alternatives (Leenstra et al. 2011; Gremmen et al. 2018).

In terms of animal suffering, if day old males are killed using the most humane methods, the practice of culling shouldn't pose more of a welfare concern than killing laying hens at the end of their productive lives. Those arguing from a capabilities perspective however would argue that these animals are denied the opportunity for a fulfilled life, they do not flourish and they certainly won't have much positive emotional experience. A utilitarian position however may argue that, as these chicks are 
utilised for reptile and raptor feed, in their absence, another feed source would need to be found-likely mice-raising further welfare (and sustainability) questions.

Aside from welfare concerns, embryo sexing may have both economic and sustainability benefits. The number of eggs placed in hatchers could be halved and the practice of manual sexing would be redundant. Although removal of manual sexing removes the stress and welfare risk of handling there may be social justice concerns where these highly skilled jobs are lost. Rearing dual purpose breeds as a solution to killing of day old males is likely to reduce the productivity either of eggs, of meat or of both, with repercussions for environmental (reduced feed efficiency, slower growth rates) and economic sustainability, but may also have sustainability benefits, collectively reducing the numbers of birds reared for eggs and meat.

\section{Genetics Companies' Effects on Breeder Bird Welfare}

\section{Housing and Management}

To develop novel strains that meet the demands of cage-free housing, genetics companies employ selection techniques which have a welfare impact on the large number of birds within their breeding flocks. Historically, breeding flocks were typically housed in individual cages to allow accurate recording of individual phenotypic data. However, in recent years steps have been taken to improve rearing facilities and management. Examples include: the provision of nest boxes (Preisinger 2017), group housing where feasible, and the cessation of beak trimming for individually housed birds.

However such steps are not universally adopted by the breeding companies. Perches, for example, are considered detrimental to egg quality and are not used by any major company with a global reach (personal communication). In this case, a decision is taken to prioritise egg quality over the behavioural needs of the birds. 'Trap nests' allow group housing of pureline females whilst enabling the collection of individual bird data on production parameters. They are used by Lohmann (see Preisinger 2017) and are being developed by Hendrix Genetics (personal communication). It seems that genetics companies are taking a proactive approach to improving welfare for its own sake.

Individual housing does not allow selection on social interaction parameters, such as aggression or injurious pecking behaviour. Group selection methods are therefore used to take into account the indirect genetic effects a bird may have on other birds within a group (Brinker et al. 2014; Ellen et al. 2014). In ideal conditions, group housing is optimal for the welfare of gregarious species such as the chicken (RSPCA 2011), however, group selection methods are not without welfare concerns. Undesirable management interventions such as beak trimming may be necessary and, in the case of 'challenge tests', birds are intentionally housed in conditions used to promote IP in order to identify families with a propensity for the behaviour.

Challenge tests may result in an overall benefit for the greater number of animals developed for commercial placement, and thus there may be sound arguments from a utilitarian perspective, but there are serious welfare concerns for the individual 
birds utilised in the selection process which are at odds with other ethical views (Nussbaum 2004; Dawkins 2008). Birds in families exhibiting high levels of IP are, by necessity, exposed to IP behaviour and, potentially, cannibalism. To ensure that beneficial behaviours are maintained throughout the commercial production period, birds are tested up to around 85 weeks of age, living their entire lives under test conditions. In some instances, these tests fall below the European legislative standards and thus are performed elsewhere, outside of the EU.

Two ethical dilemmas are presented here. Firstly, a relatively small number of birds is exposed to harsh conditions to enable a much larger proportion of commercial birds to live with lower risk of IP and, potentially, without the need for beak mutilation. Stress events, health problems and nutritional imbalances which may trigger IP outbreaks do occur in commercial production, even in well managed flocks, and can have devastating impacts on welfare. The development of robust birds that can withstand these events is therefore desirable, but the costs need to be evaluated objectively.

Secondly, tests may be carried out in a company's facilities in parts of the world where legal standards are less stringent than they are in the company's 'home' facilities. Where a European genetics company deliberately tests in countries with lower standards it raises ethical concerns, given that legislative standards may be considered to reflect what is socially acceptable (Hernandez et al. 2018). As the resulting genetics will likely be used both in the country where testing occurred and abroad, the viewpoints of all beneficiaries should be taken into account.

Even though direct responsibility for layers involves a wider spectrum of practical duties than indirect responsibility does, the companies' indirect responsibility for offspring might be considered more important because it involves many more individual animals than those under their direct care care. Hendrix Genetics and the EW Group are each indirectly responsible for some 2-3 billion layer hens globally at any given time. Others may argue that any management involving deliberate stress or deprivation is ethically unacceptable (Nussbaum 2006) and steps must be taken to resolve the issue.

\section{Wider Ethical Considerations}

The ecological footprint of egg production (Weeks et al. 2016) is highly relevant as a morally relevant concern in its own right. Regardless of geographical proximity the resources used for egg production reflect a reliance on animals and other organisms in interconnected ecosystems. The steadily improved feed efficiency of egg production (Preisinger 2017, Fig. 3) achieved through genetic improvements has helped to reduce the environmental impact of the egg industry, resulting in in savings of 56.9 million tons of feed and 8.1 million hectares of land with wheat production between 1995 and 2015 (Preisinger 2017, p. 3). However, given a historic increase in egg production in the same period, there has been no absolute saving. With the current demand for eggs globally "at a level of 75 million tonnes 
with an annual increase of 1 million tonnes each year" (Preisinger 2017), if the volume of global egg production increases at a faster pace than feed efficiency improves, then egg production will require more feed, and more land, from one year to another in real terms.

But do concerns around egg consumption and demand fall within the ethical and moral responsibility of genetics companies? In the sense that they pursue goals of increased consumption and new market penetration (Preisinger 2017), it could be argued that they do bear some responsibility. However, this cannot be argued in isolation. First, there are other actors within the chain playing a significant role, including retailers, producers, governments and consumers. Second, we must consider the potential economic and societal benefits, such as those of a nutritional nature.

Eggs are a nutritionally dense and relatively cheap food. Genetics companies make use of these health benefits of eggs to assert their role in helping to support nutritional improvements for poorer, developing countries and to justify penetration into less developed markets such as parts of Asia and Africa (Preisinger 2017). Other markets, such as Europe, North America and Japan have very little room for market development (Preisinger 2017). But how essential are eggs in helping to improve healthy diets, and is the development of markets (perhaps industrial compared with current livestock practices) a positive development in these areas?

The World Health Organisation's (WHO) (2007) report Protein and Amino Acid Requirements in Human Nutrition suggests that the nutritional value of many plantbased sources of protein, including soya, potato, rice, maize, wheat and yam is 'considerably greater than the proposed [amino acid and protein] requirement values overall', although insufficient in terms of lysine (with the exception of soya and potatoes). Whilst eggs contain overall the highest protein and amino acid values, other non-animal and non-egg sources are apparently sufficient to meet human adult reference values. Recent studies recommend moves towards more plant-based diets for environmental (Springmann et al. 2018; Willett et al. 2019) or animal ethics (Singer 2002 [1975]) reasons.

Subsistence farming in South Africa plays an important role in improving household food security, reducing dependence on market purchases and helping to drive down food prices (Baiphethi and Jacobs 2009). Within the EU, Romania has some reliance on subsistence farming as a 'safety net for the poor population living in the countryside' (Alexandri et al. 2015). Whilst we might be able to legitimise more industrial food production due to efficiencies (including environmental and economic efficiencies) this does not necessarily result in better access to cheaper food for all. This is because "problems related to the distribution of incomes at society level can seriously impact the access to food and the food security at household level' (Alexandri et al. 2015).

Although the egg industry, and the role of genetics companies, has ethical implications across all four of the impacts identified in Fig. 2, a detailed analysis of their roles and responsibilities is beyond the scope of this paper. As all agricultural production will have such impacts it is not rational to assess the egg industry based on any one impact alone. 


\section{Resolving Dilemmas}

In the global egg production system, making progress with regard to one welfare concern typically involves greater or altered challenges with regard to interrelated welfare concerns. The genetics companies have to relate to concerns for animal welfare, profitability, environmental sustainability and social justice. Incorporating these concerns in the design of breeding goals is therefore decisive. To date, however, global egg production has had a predominant focus on increasing production volumes, thus raising animal welfare and environmental sustainability concerns. To resolve this conflict, a transition to more commercial focus on quality and high-value products, and less emphasis on the quantities produced, would facilitate higher prioritisation of both animal welfare and environmental sustainability. Such a change in commercial thinking and strategy would also complement expected global development characterized by increased wealth, and hence ability to pay, and growing consciousness about animal welfare and environmental sustainability.

\section{Ideal Conditions}

In an ideal world, how should laying hens be kept? Even if animal welfare concerns are prioritized, there may be debate about the best conditions for laying hens. Consumers who prioritise natural flock sizes and a natural social life might prefer hobby-style keeping of a few hens in a coop, with regular access to outdoor space. Some would say that commercial keeping of layers on an industrial scale is necessarily incompatible with the highest welfare standards, simply because in industrial-scale egg production, commercial concerns predominate. On the other hand, professional, commercial production systems might provide controlled environments that involves better predator protection, more systematic veterinary care, and other benefits, and within such systems ideal conditions for animal welfare may still be pursued. This can be done in several ways including developing layer breeds for which high animal welfare standards are prioritised over competing concerns, and marketing these high welfare-breeds as giving extra value to ethically conscious consumers and therefore deserving of a higher price.

Given sufficient consumer demand and willingness to pay, the development of highwelfare layer breeds might not involve breeding goals aiming at improved feed efficiency or extended layer cycles. Such breeding goals should be included for high-welfare breeds only to the extent that they are beneficial for, or consistent with, animal welfare. This would imply a prioritisation of animal welfare over sustainability and productivity concerns. From a commercial perspective, such prioritisation is justified by the marked profitability of such breeds, assuming sufficient ethical consumer awareness.

\section{Minimum Standards}

\section{Transparency and Self Reporting of Welfare Data}

We acknowledge that genetics companies cannot be wholly responsible for animal welfare outcomes on farms, and recognise that besides genetic influences, 
there are also environmental and commercial influences. However, to understand and apportion responsibility to the various stakeholders, we must identify the relative contribution of each type of influence.

According to Rauw and Gomez-Raya (2014) "an animal from a population genetically selected for increased production will only be able to realise this potential in an environment in which resources are adequately supplied". The same can be said for welfare traits. A hen may have a robust skeleton less susceptible to fracture, but if her housing environment exposes her to risk of injury-for example a multi-level environment which she cannot adequately manoeuverefractures will still occur. Genetic advances may be made, but unless there is concurrent development in nutrition and management, the genetic potential for improvement will not be realised (Bain et al. 2016). System-specific management guides for each breed may help to ensure alignment between genetic potential and environmental fit, but these guides are currently primarily concerned with production potential, rather than welfare.

A level of transparency with regard to welfare traits (bone health, cannibalism, morbidity) concomitant with the current level of transparency with regard to productivity traits should be possible. After all, each of the major genetics companies is selecting on these traits and therefore must also be measuring them. Such data may be influenced by environmental factors and the quality of assessment but the same can be said equally for each productivity measure that is already freely available on each company's website.

Increased transparency about the genetic profiles of layer breeds would make it easier to apportion responsibility to the various actors within the supply chain. Moreover, producers, retailers and assurance schemes could begin to objectively select, or require, the use of breeds based on welfare performance. In turn, these welfare measures become important points of difference, which could help to drive genetic improvements in welfare similar to those seen in egg productionbut, crucially, only if there is sufficient retail and/or consumer demand for higher welfare traits.

As well as transparency in genetic output, transparency in business practice is also important. Adherence to Code EFABAR standards, the industry's code for responsible breeding, signals a company's commitment to 'supporting a sustainable future', according to the Code's web pages (CodeEFABAR 2018). That such a code exists indicates a recognition within the industry that ethical considerations must be present in their day to day operations. However, the transparency of the Code itself is limited. For a voluntary regulatory body to have any 'teeth', their standards must be made publicly available.

\section{Submitting Breeds for Independent Welfare Assessments}

Going beyond self-reporting of welfare measures by genetics companies, the formation of an independent international body to test and report on the welfare outcomes of new and existing breeds would provide a reliable reference point both for industry, farm assurance bodies and consumers. Reporting should be done on a rolling basis to take into account genetic developments. The establishment of such an 
independent welfare reporting body is practically possible-for example, there is already an established protocol used to assess commercial broiler chickens in the UK (RSPCA 2017b). It would also chime with good transparency in Corporate Social Responsibility reporting.

\section{Progressive Standards}

\section{Development of Distinct Higher Welfare Breeds}

Within the meat chicken industry there has been a drive for breed changes to address the serious welfare issues associated with fast growth rate. Some higher welfare Farm Assurance scheme standards, such as RSPCA Assured (UK) and Beter Leven (Netherlands) permit only slower growing breeds of chicken. RSPCA Assured further stipulates a requirement for independently verified higher welfare outcomes, for example in relation to gait score (RSPCA 2017b). For organic chicken production, where the legal slaughter age is higher than for standard production, these slower growing breeds may also be used. The 'Better Chicken Commitment' (European Chicken Commitment 2018; Joint Animal Protection Statement on the Welfare of Broiler Chickens 2018) campaigns, are seeking European- and USA-wide improvements to rearing standards, including breed. The relative economical cost and resource use associated with rearing slower growing breeds of chicken is greater. However, a line has been drawn under what is considered acceptable in terms of welfare, higher welfare breeds are available, and retailers and food manufacturers are committing to use them (https://betterchicken.org.uk/).

Whilst there are clear welfare concerns in laying hens linked to high productivity (Candelotto et al. 2017; Nicol 2015), there is as yet no candidate "higher welfare breed" with which to pin a higher welfare standard to. A high welfare breed would be expected to achieve, for example, frequent ranging, positive social interactions and good health outcomes, alongside low levels of IP and KBD. However, whilst there are breed differences and thus genetic influences on these two welfare issues, the genetic improvements within current commercial lines would not solve these issues, merely reduce problems by degrees.

A question then is whether the laying hen industry, retailers and consumers alike could accept a change akin to that taking place in the meat chicken industry i.e., use of slow growth lines; and whether the genetics companies can provide it. Birds which have not been selected for productivity traits may have better welfare outcomes, for example reduced KBD (Candelotto et al. 2017), and improved welfare may therefore be at the cost of productivity. Consumers are willing to pay for freerange eggs because they believe that outdoor access and fresh air are important features of higher welfare systems, and that birds within them are not only 'happier' but also 'healthier' (Pettersson et al. 2016). However, whether they are willing to pay an additional cost for higher welfare outcomes that are more difficult to define in marketing terms (reduced risk of IP or KBD) is less clear. Indeed a focus on these negative aspects represents a risk to well-intentioned efforts of the industry. 
Given the monopolisation of the market by 4 genetics companies, there may be a sense that the farming industry currently 'gets what it's given' with regard to hen genetics (Howard, 2016) and the development of new-independently verifiedhigher welfare breeds could offer choice in an otherwise homogenous market.

Both Hendrix Genetics and EW Group do-to varying degrees-tailor layer breeds to meet market demand and local societal expectations. By tailor-making breeds in this fashion, they adjust to what is feasible and perceived as requiredinevitably resulting in some breeds being destined specifically for the higher welfare (e.g. cage-free) markets. However, this is almost certainly market, rather than ethically, driven and, as yet, there is no clear higher welfare breed as determined by independent welfare testing.

From an ethical perspective, we could argue that, whenever a genetics company's standards are higher than societal expectations locally require, the company is progressive with regards to animal welfare standards. Conversely, whenever a genetics company's standards are lower than societal expectations locally require, it is reactionary with regard to animal welfare standards. From an animal welfarist viewpoint progressive genetics companies are preferable, and to be progressive compared with societal expectations is morally laudable. Being «one step ahead» of increasing animal welfare expectations could also be seen as strategically positioning the companies for a future world market characterised by a higher level of consumer consciousness about animal welfare issues.

\section{Thinking in Terms of Minimum Standards for What is Morally Permissible}

Legislation is 'reflective of societal expectations for basic animal care' (Hernandez et al. 2018) and provides the baseline standard to which companies should adhere. However, legislative standards differ dependent upon the originating authority. European-based genetics companies sometimes make use of the differing legislative standards to their practical advantage, for example by performing 'challenge tests' outside of the EU. It can be argued that the most easily morally defensible position would be to operate to a single standard, with this being the highest legal standards of the countries in which they operate. However, breeding to other, non-European standards might in some cases be defended by reference to the need for testing in more realistic settings for other markets.

To go beyond simply achieving the societal or legal minimum standards and to begin to operate in the realms of being 'morally progressive', companies should look beyond adhering to the legal minimum and seek out welfare improvements purely for the sake of welfare improvement itself. In some aspects of production, companies already independently operate above legal minimum standards, for example by the inclusion of environmental enrichment within their individual-bird housing facilities and the development of trap nests to allow group housing. This appears to be purely in the pursuit of improved welfare and thus can be considered morally progressive. The phasing out of breeds with poor welfare outcomes regardless of market demand, offering only those with a higher welfare potential, would also be morally laudable. 
However, being morally progressive does not have to be detrimental to business. Seeking out developments which improve welfare and meet with customer and consumer demands can make good business sense. Being a leader in the development of a genuinely robust hen with acceptable — if not leading — productivity could put one genetic company ahead of the competition.

\section{Conclusion}

Genetics companies have a wide range of ethical considerations to attend to, including those relating to sustainability, human health and animal welfare. These ethical considerations sometimes align, but often conflict. Regarding animal welfare, solutions to one welfare problem often result in new or exacerbated welfare concerns elsewhere. However, for egg producers, retailers and consumers to make informed ethical choices genetics companies must be more transparent in relation to the welfare outcomes achieved for different breeds. They should also adopt the highest legal standards globally, while offering robust breeds for all market segments, and consider phasing out poor welfare breeds.

As a 'moral optimum' we suggest that genetics companies pursue the development of truly higher welfare breeds, where welfare traits are prioritised over productivity and birds are capable of withstanding the challenges of modern cage-free production. We furthermore suggest that an independent body be established to carry out welfare assessments of commercial breeds to provide objective measures of welfare outcomes.

Acknowledgements This article is the outcome of a Short-Term Scientific Mission organised and funded by COST action CA15134 «Synergy for preventing damaging behaviour in group housed pigs and chickens» (GroupHouseNet). The STSM included a two-week research visit to University of Stavanger, Norway, by Mia Fernyhough, hosted by Morten Tønnessen. We thank Hendrix Genetics for hosting another research visit by Mia Fernyhough and providing information about their practices. We further extend our gratitude to James Yeates, who in an early phase of our work contributed with ideas concerning the design of this article. At the time he worked as Chief Veterinary Officer of the Royal Society for the Prevention of Cruelty to Animals.

Conflict of interest Teun van de Braak is a geneticist at Hendrix Genetics, a company that is being critically discussed in this article. Mia Fernyhough works at Royal Society for the Prevention of Cruelty to Animals, a NGO with a progressive, specific agenda in matters of animal welfare.

Open Access This article is distributed under the terms of the Creative Commons Attribution 4.0 International License (http://creativecommons.org/licenses/by/4.0/), which permits unrestricted use, distribution, and reproduction in any medium, provided you give appropriate credit to the original author(s) and the source, provide a link to the Creative Commons license, and indicate if changes were made.

\section{References}

Alexandri, C., Lucaa, L., \& Kevorchiana, C. (2015). Subsistence economy and food security: The case of rural households from Romania. Procedia Economics and Finance, 22, 672-680.

Bain, M. M., Nys, Y., \& Dunn, I. C. (2016). Increasing persistency in lay and stabilising egg quality in longer laying cycles: What are the challenges? British Poultry Science, 57, 330-338. 
Baiphethi, M. N., \& Jacobs, P. T. (2009). The contribution of subsistence farming to food security in South Africa. Agrekon, 48, 459-482.

Bal, A. (2012). Novogen makes good progress. Retrieved Feb 14, 2018 from http://www.poultrywor ld.net/Breeders/General/2012/5/Novogen-makes-good-progress-WP010347W/.

Bennewitz, J., Bögelein, S., Stratz, P., Rodehutscord, M., Piepho, H. P., Kjaer, J. B., et al. (2014). Genetic parameters for feather pecking and aggressive behavior in a large F2-cross of laying hens using generalized linear mixed models. Poultry Science, 93(4), 810-817.

Besbes, B., Tixier-Boichard, M., Hoffmann, I., \& Jain, G. L. (2007). Future trends for poultry genetic resources. In Proceedings of the international conference poultry in the twenty-first century: Avian influenza and beyond, At Bangkok, Thailand.

Big Dutchman. (2016). PickPuck permanently occupies the layers and wears down the beak in a natural way. Retrieved March 05, 2018, from https:/www.bigdutchman.com/en/egg-production/news/detai 1/pickpuck-permanently-occupies-the-layers-and-wears-down-the-beak-in-a-natural-way.html.

Bridle, B. W., Julian, R., Shewen, P. E., Vaillancourt, J.-P., \& Kaushik, A. K. (2006). T lymphocyte subpopulations diverge in commercially raised chickens. Canadian Journal of Veterinary Research, 70, $183-190$.

Brinker, T., Bijma, P., Visscher, J., Rodenburg, T. B., \& Ellen, E. D. (2014). Plumage condition in laying hens: genetic parameters for direct and indirect effects in two purebred layer lines. Genetics Selection Evolution, 46, 33.

Candelotto, L., Stratmann, A., Gebhardt-Henrich, S. G., Rufener, C., van de Braak, T., \& Toscano, M. J. (2017). Susceptibility of keel bone fracture in laying hens and the role of genetic variation. Poultry Science, 96, 3517-3528.

CodeEFABAR. (2018). Retrieved Feb 04, 2018, from http://www.responsiblebreeding.eu/.

D'Silva, J., \& Webster, J. (Eds.). (2010). The meat crisis: Developing more sustainable production and consumption. London: Earthscan.

Dawkins, M. S. (2008). The science of animal suffering. Ethology, 114(10), 937-945.

Dawkins, M. S. (2016). Animal welfare and efficient farming: Is conflict inevitable? Animal Production Science, 52, 201-208.

De Haas, E. N., Bolhuis, E., de Jong, I. C., Kemp, B., Janczak, A. M., \& Rodenburg, T. B. (2014a). Predicting feather damage in laying hens during the laying period. Is it the past or is it the present? Applied Animal Behaviour Science, 160, 75-85.

De Haas, E. N., Bolhuis, J. E., Kemp, B., Groothuis, T. G. G., \& Rodenburg, T. B. (2014b). Parents and early life environment affect behavioral development of laying hen chickens. PLoS ONE, 9(3), e90577. https://doi.org/10.1371/journal.pone.0090577.

Ellen, E. D., Rodenburg, T. B., Albers, G. A. A., Bolhuis, J. E., Camerlink, I., Duijvesteijn, N., et al. (2014). The prospects of selection for social genetic effects to improve welfare and productivity in livestock. Frontiers in Genetics, 5, 377.

European Chicken Commitment. (2018). Retrieved Feb 20, 2018, from http://welfarecommitments.com/ europeletter/.

FAOSTAT. (2018). Retrieved Feb 20, 2018, from http://www.fao.org/faostat/en/\#data/QL.

Fleming, R. H., McCormack, H. A., McTeir, L., \& Whitehead, C. C. (2004). Incidence, pathology and prevention of keel bone deformities in the laying hen. British Poultry Science, 45, 320-330.

Fleming, R. H., McCormack, H. A., McTier, L., \& Whitehead, C. C. (2006). Relationships between genetic, environmental and nutritional factors influencing osteoporosis in laying hens. British Poultry Science, 47, 742-755.

Fleming, R. H., Whitehead, C. C., Alvey, D., Gregory, N. G., \& Wilkins, L. J. (1994). Bone strength and breaking strength in laying hens housed in different husbandry systems. British Poultry Science, 35 , 651-662.

Galli, R., Preusse, G., Uckermann, O., Bartels, T., Krautwald-Junghanns, M. E., Koch, E., et al. (2017). In ovo sexing of chicken eggs by fluorescence spectroscopy. Analytical and Bioanalytical Chemistry, 409, 1185-1194.

Garnham, L., \& Løvlie, H. (2018). Sophisticated fowl: The complex behaviour and cognitive skills of chickens and red junglefowl. Behavioural Science, 8, 13.

Gebhardt-Henrich, S. G., Pfulg, A., Fröhlich, E. K. F., Käppeli, S., Guggisberg, D., Liesegang, A., et al. (2017). Limited associations between Keel Bone Damage and bone properties measured with computer tomography, three-point bending test, and analysis of minerals in Swiss laying hens. Frontiers in Veterinary Science, 4, 128. 
Gremmen, B., Bruijnis, M. R. N., Block, V., \& Stassen, E. N. (2018). A public survey on handling male chicks in the Dutch egg sector. Journal of Agricultural and Environmental Ethics, 31, 93-107.

Grumbles, L. C. (1959). Cage layer fatigue (cage paralysis). Avian Diseases, 3, 122-125.

Harlander-Matauschek, A., Rodenburg, T. B., Sandilands, V., Tobalske, B. W., \& Toscano, M. J. (2015). Causes of keel bone damage and their solutions in laying hens. World's Poultry Science Journal, 71, $461-472$.

Haynes, R. P. (2008). Animal welfare. Competing conceptions and their ethical implications. Dordrecht: Springer.

Heerkens, J. L., Delezie, E., Rodenburg, T. B., Kempen, I., Zoons, J., Ampe, B., et al. (2016). Risk factors associated with keel bone and foot pad disorders in laying hens housed in aviary systems. Poultry Science, 95, 482-488.

Hendrix Genetics. (2018). Animal welfare initiatives. Retrieved Feb 14, 2018, from https://www.hendr ix-genetics.com/en/hendrix-genetics/sustainability/animal-welfare/.

Hernandez, E., Fawcett, A., Brouwer, E., Rau, J., \& Turner, P. V. (2018). Speaking up: Veterinary ethical responsibilities and animal welfare issues in everyday practice. Animals, 8, 15.

Howard, P. H. (2016). Enforcing the new enclosures: Agricultural inputs. In P. H. Howard (Ed.), Concentration and power in the food industry, who controls what we eat? (pp. 104-123). London: Bloomsbury.

International Egg Commission. (2018a). Annual Review 2018. https://www.internationalegg.com/docum ent_category/publications/.

International Egg Commission. (2018b). The IEC Journal 31. https://www.internationalegg.com/docum ent_category/publications/.

Jaffe, G. (2018). European Union opinion on gene editing: Insightful or missed opportunity? Retrieved February 14, 2018 from https://allianceforscience.cornell.edu/blog/2018/01/european-union-opini on-on-gene-editing-insightful-or-missed-opportunity/.

Joint Animal Protection Statement on the Welfare of Broiler Chickens. (2018). Retrieved Feb 20, 2018, from http://welfarecommitments.com/letter.pdf.

Lambton, S. L., Nicol, C. J., Friel, M., Main, D. C. J., McKinstry, J. L., Sherwin, C. M., Walton, J., \& Weeks, C. A. (2013). A bespoke management package can reduce levels of injurious pecking in loose-housed laying hen flocks. Veterinary Record, 172, 423-426.

Leenstra, F., Munnichs, G., Beekman, V., van den Heuvel-Vromans, E., Aramyan, L., \& Woelders, H. (2011). Killing day-old chicks? Public opinion regarding potential alternatives. Animal Welfare, 20, $37-45$.

Marino, L. (2017). Thinking chickens: A review of cognition, emotion, and behavior in the domestic chicken. Animal Cognition, 20, 127-147.

Muir, W. M., Cheng, H.-W., \& Croney, C. (2014). Methods to address poultry robustness and welfare issues through breeding and associated ethical considerations. Frontiers in Genetics, 5, 93-103.

Muir, W. M., et al. (2008). Genome-wide assessment of worldwide chicken SNP genetic diversity indicates significant absence of rare alleles in commercial breeds. Proceedings of the National Academy of Sciences, 105, 17312-17317.

Mullan, S. M., Szmaragd, C., Wrathall, J. H. M., Cooper, M., Jamieson, J., Bond, A., et al. (2016). Animal welfare initiatives improve feather cover of cage-free laying hens in the UK. Animal Welfare, 25, 243-253.

Nasr, M., Browne, W. J., Caplen, G., Hothersall, B., Murrell, J. C., \& Nicol, C. J. (2013). Positive affective state induced by opioid analgesia in laying hens with bone fractures. Applied Animal Behaviour Science, 147, 127-131.

Nasr, M. A. F., Murrell, J., Wilkins, L. J., \& Nicol, C. J. (2012). The effects of keel bone fracture on egg production parameters, mobility and behavior in individual laying hens. Animal Welfare, 21, $127-135$.

Nicol, C. J. (2015). Genetics and domestication. In The behavioural biology of chickens (pp. 1-14). Croydon: CABI.

Nicol, C. J. (2019). Feather pecking in laying hens, why they do it and welfare implications. In Poultry feathers and skin. CABI.

Nussbaum, M. C. (2004). Beyond 'compassion and humanity'. Justice for nonhuman animals. In C. R. Sunstein \& M. C. Nussbaum (Eds.), Animal rights (pp. 299-320). Oxford: Oxford University Press.

Nussbaum, M. (2006). Frontiers of justice: Disability, nationality, species membership. Cambridge: Harvard University Press. 
Pettersson, I. C., Weeks, C. C., Wilson, L. R. M., \& Nicol, C. J. (2016). Consumer perceptions of freerange laying hen welfare. British Food Journal, 118, 1999-2013.

Preisinger, R. (2017). Innovative layer genetics to handle global challenges in egg production. British Poultry Science, 59, 1-6.

Rauw, W. M., \& Gomez-Raya, L. (2014). Genotype by environment interaction and breeding for robustness in livestock. Frontiers in Genetics, 6, 310.

Regan, T. (1983). The case for animal rights. Berkeley: University of California Press.

Regmi, P., Nelson, N., Steibel, J. P., Anderson, K. E., \& Karcher, D. M. (2016). Comparisons of bone properties and keel deformities between strains and housing systems in end-of-lay hens. Poultry Science, 95, 2225-2234.

Riber, A. B., \& Hinrichsen, L. K. (2017). Welfare consequences of omitting beak trimming in barn laying hens. Frontiers in Veterinary Science, 4, 222.

RSPCA. (2011). Domestic fowl: Good practice for housing and care. Horsham: RSPCA.

RSPCA. (2017a). RSPCA response to genomics and genome-editing inquiry. Retrieved March 01, 2018, from http://data.parliament.uk/writtenevidence/committeeevidence.svc/evidencedocumen t/science-and-technology-committee/genomics-and-genomeediting/written/46331.html.

RSPCA. (2017b). RSPCA welfare standards for meat chickens. Retrieved Feb 04, 2018, from https:// science.rspca.org.uk/sciencegroup/farmanimals/standards/chickens.

Rufener, C., Baur, S., Stratmann, A., \& Toscano, M. J. (2018). Keel bone fractures affect egg laying performance but not egg quality in laying hens housed in a commercial aviary system. Poultry Science, 98, 1589-1600. https://doi.org/10.3382/ps/pey544.

Sandilands, V., Moinard, C., \& Sparks, N. H. C. (2009). Providing laying hens with perches: Fulfilling behavioural needs but causing injury? British Poultry Science, 50, 395-406.

Sariozkan, S., Kara, K., \& Güçlü, B. K. (2016). Applicability of non-feed removal programs to induce molting instead of the conventional feed withdrawal method in brown laying hens. Revista Brasileira de Ciência Avícola, 18, 535-541.

Sherwin, C. M., Richards, G. J., \& Nicol, C. J. (2010). Comparison of the welfare of layer hens in 4 housing systems in the UK. British Poultry Science, 51, 488-499.

Singer, P. (2002 [1975]). Animal liberation. New York: Random House Inc.

Smulders, T. V. (2017). The avian hippocampal formation and the stress response. Brain, Behavior and Evolution, 90(1), 81-91.

Springmann, M., et al. (2018). Options for keeping the food system within environmental limits. Nature, 562, 519-525.

Stratmann, A., Fröhlich, E. K., Gebhardt-Henrich, S. G., Harlander-Matauschek, A., Würbel, H., \& Toscano, M. J. (2015). Modification of aviary design reduces incidence of falls, collisions and keel bone damage in laying hens. Applied Animal Behaviour Science, 165, 112-123.

Stratmann, A., Fröhlich, E. K., Gebhardt-Henrich, S. G., Harlander-Matauschek, A., Würbel, H., \& Toscano, M. J. (2016). Genetic selection to increase bone strength affects prevalence of keel bone damage and egg parameters in commercially housed laying hens. Poultry Science, 5, 975-984.

Su, G., Kjaer, J. B., \& Sørensen, P. (2005). Variance components and selection response for featherpecking behavior in laying hens. Poultry Science, 84, 14-21.

Tao, S. (2012). Trends in China's poultry breeder grandparent stock. Retrieved Jan 29, 2019, from http://www.efeedlink.com/contents/06-08-2012/92bca385-ce77-4be5-9750-0c22ee18fda8-0143. html.

Tarlton, J. F., Wilkins, L. J., Toscano, M. J., Avery, N. C., \& Knott, L. (2013). Reduced bone breakage and increased bone strength in free range laying hens fed omega-3 polyunsaturated fatty acid supplemented diets. Bone, 52, 578-586.

The Poultry Site. (2007). Researcher delves into why naturally blind chickens perform better. Retrieved Feb 05, 2018, from http://www.thepoultrysite.com/poultrynews/12329/researcher -delves-into-why-naturally-blind-chickens-perform-better/.

Toscano, M. J. (2018). Skeletal problems in contemporary commercial laying hens. In J. A. Mench (Ed.), Advances in poultry welfare science (1st ed., pp. 151-174). Cambridge: Woodhead Publishing.

Toscano, M. J., Booth, F., Wilkins, L. J., Avery, N. C., Brown, S. B., Richards, G., et al. (2015). The effects of long (C20/22) and short (C18) chain omega-3 fatty acids on keel bone fractures, bone biomechanics, behavior, and egg production in free-range laying hens. Poultry Science, 94, 823-835.

Uitdehaag, K. A., Komen, H., Rodenburg, T. B., Kemp, B., \& van Arendonk, J. A. M. (2008). The novel object test as predictor of feather damage in cage-housed Rhode Island Red and White Leghorn laying hens. Applied Animal Behaviour Science, 109, 292-305. 
Warren, D. C. (1937). Physiological and genetic studies of crooked keels in chickens. Kansas State College of Agriculture, Technical Bulletin 44. Retrieved Dec 20, 2018, from https://www.ksre.k-state .edu/historicpublications/pubs/STB044.PDF.

Weeks, C. A., Lambton, S. L., \& Williams, A. G. (2016). Implications for welfare, productivity and sustainability of the variation in reported levels of mortality for laying hen flocks kept in different housing systems: A meta-analysis of ten studies. PLoS ONE, 11(1), e0146394.

Weeks, C. A., Newton, J., McKinstry, J. L., Friel, M., Walton, J., Edge, S., Main, D. C. J., Nicol, C. J., \& Sherwin, C. M. (2011). Predicting the economic costs and benefits of changes aimed at reducing levels of injurious pecking on free-range layer farms. In Poster presentation: UFAW International Symposium, Portsmouth 28-29 June 2011: Making animal welfare improvements: economic and other incentives and constraints.

Weissmann, A., Reitemeier, S., Hahn, A., Gottschalk, J., \& Einspanier, A. (2013). Sexing domestic chicken before hatch: A new method for in ovo gender identification. Theriogenoloy, 80, 199-205.

Wilkins, L. J., McKinstry, J. L., Avery, N. C., Knowles, T. G., Brown, S. N., Tarlton, J., et al. (2011). Influence of housing system and design on bone strength and keel bone fractures in laying hens. Veterinary Record, 169, 414.

Willett, W. et al. (2019). Food in the Anthropocene: The EAT-Lancet Commission on healthy diets from sustainable food systems. Retrieved Feb 17, 2019, from https://eatforum.org/content/uploa ds/2019/01/EAT-Lancet_Commission_Summary_Report.pdf.

Windhorst, H.-W. (2019). Patterns and dynamics of China's egg industry. Retrieved Feb 17, 2019, from https://zootecnicainternational.com/focus-on/patterns-dynamics-chinas-egg-industry/.

World Health Organization. (2007). Protein and amino acid requirements in human nutrition. In: Report of a joint WHO/FAO/UNU, expert consultation. Technical report series no 935. Geneva: WHO.

Publisher's Note Springer Nature remains neutral with regard to jurisdictional claims in published maps and institutional affiliations. 